\title{
Do alcohol pricing and availability policies have differential effects on sub-populations? A commentary
}

\author{
Norman Giesbrecht ${ }^{1,2}$, Ashley Wettlaufer ${ }^{1}$, Samantha Cukier $^{3}$, Gillian Geddie ${ }^{4}$, André-Henrique Gonçalves ${ }^{5}$, \\ and Emilene Reisdorfer ${ }^{1}$ \\ ${ }^{1}$ Centre for Addiction and Mental Health, Toronto, Canada \\ ${ }^{2}$ Dalla Lana School of Public Health, University of Toronto, Toronto, Canada \\ ${ }^{3}$ Johns Hopkins Bloomberg School of Public Health, Center on Alcohol Marketing \& Youth, Baltimore, Maryland, United States \\ ${ }^{4}$ Royal Holloway University of London, London, United Kingdom \\ ${ }^{5}$ Federal University of Bahia, Salvador, Brazil
}

\begin{abstract}
Aims: Numerous policies have been shown to reduce the harm from alcohol; however, not all sub-populations respond similarly to policy interventions. This paper explores the specific effects of alcohol pricing policies and controls regarding physical availability on different types of harms from alcohol as well as on different sectors of the population, including impacts by gender, age, and drinking patterns.
\end{abstract}

Design, Setting, Participants, and Measures: We focus on two dimensions. The first is alcohol pricing and taxation; the second is alcohol availability, comprising type of alcohol control system, outlet density, and hours/days of sale. We focused on peer-reviewed research and reviews published from 2005-2015, using several databases: PsycINFO, MEDLINE/PubMed, and Cochrane.

Findings: Precautionary alcohol prices have substantial harm reduction potential, particularly among youth and high-risk drinkers. Restrictions on outlet densities and hours/days of sale impact the drinking patterns of underage youth, reduce high-risk drinking, and reduce alcohol-related harm. A reduction in prices or an increase in alcohol availability are associated with increase in high-risk drinking or alcohol-related harm.

Conclusions: Future work should examine these policy measures in light of socioeconomic status and cultural factors, as well as impacts of policy interventions on evidence of harm to others from alcohol.

\section{Introduction and Background}

Alcohol is a major contributor to disease and disability, ranking fifth internationally, and higher in some countries (Lim et al., 2012). A range of alcohol policies and interventions have been assessed with regard to their impact in reducing consumption, high-risk drinking, or harm from alcohol (Anderson, Chisholm, \& Fuhr, 2009; Babor et al., 2003, 2010; Brand et al., 2007; Canadian Public Health Association, 2011; Crombie, Irvine, Elliott, \& Wallace, 2007; Giesbrecht, Stockwell, Kendall, Strang, \& Thomas, 2011; Giesbrecht et al., 2013; Karlsson \& Österberg, 2001; Nelson et al., 2013; Stockwell, Gruenewald, Toumbourow, \& Loxley, 2005). The World Health Organization (WHO, 2010) proposed ten recommendations to reduce alcohol-related harm as part of their Global Alcohol Strategy; these included alcohol pricing/taxation and strategies to reduce the availability of alcohol.

In this paper we address the following research question: Is there a differential impact of two general measuresalcohol pricing/taxation and availability of alcohol—on different sectors of the population? Our availability focus is on four dimensions: density of alcohol outlets, days of sale, hours of alcohol sale, and type of alcohol retailing system. We focus primarily on publications from 2005 to 2015.

This research question is relevant to the interplay between population-level policies and interventions and more targeted interventions (Babor et al., 2010; WHO, 2010). It also has a bearing on the political question of whether the state should be controlling alcohol sales if such controls

Correspondence: Norman Giesbrecht, PhD, Social \& Epidemiological Research Dept. Centre for Addiction \& Mental Health, 33 Russell St., Toronto, Ontario M5S 2S1 Canada. Telephone: 416-535-8501 ext. 36895; Fax 416-595-6899; E-mail: norman.giesbrecht@camh.ca

Financial support: Work on this paper was made feasible by in-kind support from the institutions with which the authors are affiliated.

Declaration of interest: The authors have no conflict of interest to declare..

Keywords: alcohol pricing, alcohol availability, differential effects, gender, age, drinking patterns, alcohol-related harm 
only impact the low-risk drinker and do not curtail heavy drinking or harm from alcohol.

Going back forty years, the differential impact of these policies was not a central focus by Bruun et al. (1975). In Chapter Six they discuss "alcohol control policies," including a discussion of both economic and physical controls on availability. They note that changes in the availability of alcohol have been shown to impact the drinking of dependent individuals; beyond that there is little mention of differential impacts of the other alcohol policies that they discuss.

In Edwards et al. (1994), the chapter on alcohol pricing points to the impacts of alcohol pricing on heavy drinkers, and the discussion of access to alcohol and effects of availability on consumption notes that these measures have been shown to impact alcohol-related problems. Nevertheless, difference by gender, age, socioeconomic status (SES), or cultural background are not noted. However, Edwards et al. (1994, pp. 140-141) report on controls that impact intoxicated persons or heavy consumers. Some years later, in Babor et al. (2010), there is frequent reference to differential impacts of alcohol policies (e.g., drinking and driving counter-measures and youth, and alcohol marketing and youth) likely indicating, in part, that the research base had expanded substantially in 16 years.

Some years ago Ashton et al. (1989) assessed how much alcohol tax was paid by 3,010 respondents to a New Zealand survey. They found that taxes account for less than $1 \%$ of household income for all income groups and did not constitute a substantial regressive burden on the lowest income groups, which tended to purchase less alcohol than those with higher incomes. Chaloupka, Grossman, and Saffer (2002) noted that price of alcohol influences consumption among youth and young adults: raising the price can reduce drinking and driving and a number of other alcohol-related harms. An earlier analysis by Grossman, Chaloupka, Saffer, and Laixuthai (1995), focusing on individual and state-level data sets between 1974-1989, found high price sensitivity among American youth.

The theme of differential impacts is also evident in Room (2002) and Mäkelä, Rossow, and Tryggvesson (2002) in their reviews of studies in the Nordic countries. Room (2002) provides an overview of differential impacts of changes in alcohol policies and natural experiments over a number of decades. In one chapter, Mäkelä et al. (2002) summarize 50 years of Nordic studies noting considerable heterogeneity in the findings and some common themes: heavier drinkers are more likely to be affected by policy changes than less frequent drinkers; less socially integrated drinkers are also more likely to be impacted. In an essay referring to the Nordic experiences in changes in alcohol policies Room (2004) notes that "the effect of policy changes on rates of alcohol-related health and social harms is often greater than the effect on the total consumption level” (50).

\section{Methods}

We focused on research published in the last 11 years (2005-2015) to keep the undertaking manageable and document the most recent research. We searched for relevant peer-reviewed publications (reviews and original articles) from 2005 to 2015 in multiple databasesPsycINFO, MEDLINE/PubMed, and Cochrane Reviewsusing relevant MeSH terms and other descriptors for each database; these included alcohol drinking, alcoholism, alcoholic beverages, legislation and jurisprudence, prevention and control, and supply and distribution. Key words were used to build the research strategy; these included alcohol, drink*, price, tax, monopoly, hours of sale, days of sale, availability , access, alcohol control, outlet density, polic*, impact, and review. Since we included reviews and meta-analyses published from 2005 forward, some of the original studies synthesized in these reviews would have been published before 2005. Titles and abstracts were screened looking for studies that met our inclusion criteria-those that a) evaluated the impact of a change in alcohol pricing or alcohol availability (control system, outlet density, hours or days of sale); b) examined the impact of these policies on at least one of several subpopulations; and c) assessed impact on at least one of three outcomes: overall alcohol consumption of participants, high-risk drinking, or alcohol-related harms. Only English studies were included.

\section{Results}

\section{Alcohol pricing and taxation.}

The impacts of alcohol pricing have been a focus of numerous analyses (e.g., Brynes, Shakeshaft, Petrie, \& Doran, 2013; Ludbrook, Holmes, \& Stockwell, 2014; Seaman, Edgar, \& Ikegwuonu, 2013; Stockwell et al., 2012, 2013). A common finding is that alcohol pricing or taxation was inversely related to consumption (Chaloupka et al., 2002; Gallet, 2007; Goodman, 2009; Patra, Giesbrecht, Rehm, Bekmuradov, \& Popova, 2012; Wagenaar, Salois, \& Komro, 2009).

Impacts by gender or SES: Herttua, Mäkelä, Martikainen, and Sirén (2008) and Helakorpi, Mäkelä, and Uutela (2010) examined the impacts of significant reductions in alcohol prices in Finland in 2004. Following this price change, moderate to heavy drinking increased mostly among women with lower education, while the highest increases in heavy episodic drinking among women were found among those with higher levels of education. Among men, both moderate to heavy drinking and heavy episodic drinking increased in the lowest education group.

Impacts by age: A number of studies have examined impacts of alcohol pricing on youth (e.g., Adams \& Effertz, 2010; Baldwin, Stogner, \& Miller, 2014; Chick, 2011; Grube \& Nygaard, 2005; Jones \& Barry, 2011; O’Mara et al., 2009; Paschall, Grube, \& Kypri, 2009; Ponicki, Gruenewald, \& LaScala, 2007; Rose, Smith, \& Segrist, 2010). Xin and Chaloupka (2011) draw attention to the 
inverse relationship between price and the consumption of alcohol among adolescents and young adults. They also noted that raising prices of alcoholic beverages reduced heavy or chronic drinking among adults and postponed dependence (Xin \& Chaloupka, 2011). Foster and Ferguson's (2014) review, focusing mainly on college or high school populations, found that "preloading" was mainly motivated by price and achieving intoxication and associated with greater consumption, intoxication, and alcohol-related risks. Saffer and Dave (2006) examined alcohol price effects on adolescents, reporting that price effects are generally larger for females relative to males. Increasing drink prices and morning classes or other academic requirements may contribute to preventing heavy drinking among college students (Skidmore \& Murphy, 2011). A small-scale experiment involving 81 Australian and 74 New Zealand college students found that social norms appeared to be stronger than price effects in both college groups (Parsons \& Stephenson, 2013). Jones and Smith (2011) conducted focus groups with 85 participants, aged 16-25, in Australia and concluded that point-of-sale promotions involving price and volume discounts had a strong impact on youth in encouraging purchasing of increased volumes of alcohol.

Impacts by drinking patterns: A meta-analysis by Wagenaar et al. (2009) examined 112 studies and found 10 studies of the effects of alcohol prices or taxes on various indicators of heavy drinking. They report, "All but one study found an inverse effect, and eight of 10 studies found statistically significant effects at the study level” (p. 187).

Impacts by type of alcohol-related harm: Wagenaar, Tolber, and Komro (2010) and Xin and Chaloupka (2011), among others (Andréasson, Holder, Norström, Österberg, \& Rossow, 2006; Diaz, Chaloupka, \& Jernigan, 2015; Lhachimi et al., 2012; Razvodovsky, 2013), have examined the impacts of alcohol prices or taxes on alcohol-related harms. A systematic review by Wagenaar et al. (2010) identified 50 articles on the effects of alcohol tax and price policies on morbidity and mortality, including cirrhosis death rates, other chronic diseases, violence, suicide, traffic-related events and death, sexually transmitted diseases (STDs), and risky sexual behavior. Based on the studies that they reviewed, the authors concluded that doubling the alcohol tax would reduce alcohol-related mortality by an average of $35 \%$, traffic crash deaths by $11 \%$, STDs by $6 \%$, violence by $2 \%$, and crime by $1.4 \%$.

Xin and Chaloupka (2011) identified an increase in taxes was associated with a decrease in fatal motor-vehicle crash rates, reduced prevalence of rape and robbery, decline in family violence among youth, and reduced prevalence of STDs. They found that a decline in prices was associated with an increase in violence and trauma, and with an inverse relationship with chronic disease and suicide rates.

Bloomfield et al. (2009) found a $26 \%$ increase in the number of acute alcohol intoxication hospitalizations among youth aged 15 years and younger after a reduction in alcohol taxes in Denmark in 2003 and 2005. In Finland in 2004-2005, after a reduction in alcohol prices, the rates for deaths from liver cirrhosis went up by almost half, while consumption increased only $10 \%$, suggesting that the price decrease had the greatest impact on the heaviest drinkers (Mäkelä \& Österberg, 2009).

Room et al. (2013) examined the impacts of a decrease in alcohol taxes in Denmark and Finland, using routine statistical register data and survey data for multiple years. While they found an increase in harm as measured by archival data, self-reported survey data did not show an increase in consumption or self-reported harms.

Lin and Liao (2014) examined alcohol harms in Taiwan from 1996 to 2010 using a data base on alcohol-attributable disease. During this time there was a tax rate increase (2002) and a decrease (2009). They found a significant decline in quarterly adjusted hospital inpatient charges following the 2002 tax increase.

Using autoregressive integrated moving average models, Saar (2015) examined the effect of alcohol excise taxes on traffic crashes involving intoxicated drivers in Estonia between 1998 and 2013. The author concluded that "changes in alcohol taxes explain a large part of the variation in traffic events” (p. 217).

Wagenaar, Livingston, and Staras (2015) focused on the effects of a 2009 increase in alcohol taxes across all types of beverages in Illinois on alcohol-related motor vehicle crashes. They used an interrupted time-series design with data for 104 months before and 28 months after the tax change. They found a $26 \%$ reduction in fatal motor-vehicle crashes, with similar changes among drivers with high levels of impairment, and a greater impact on drivers under age 30 than those 30 or older. In a parallel study (Staras, Livingston, Christou, Jernigan, \& Wagenaar, 2014) focusing on an alcohol tax increase in Illinois, the authors found a $21 \%$ decrease in state-wide rates of gonorrhea, with significant reductions in non-Hispanic Blacks, especially those aged 25-29.

Finally, a research note by Zatoriskim, Sulkowska, Zatoński, Herbeć, and Muszyńska (2015) points to the negative impacts on health linked to lowering of alcohol taxes in Lithuania (Grabauskas et al., 2009) and Finland (Mäkelä \& Österberg, 2009). They note that a reduction in vodka prices in Poland was followed by a sharp increase in sales and yearly increase in mortality rates attributable to alcohol.

\section{Availability - control system, outlet density, days and hours of sale}

The impacts of these interventions have been reported in various analyses and reviews (Babor et al., 2010; Campbell et al., 2009; Fone et al. 2012; Hahn et al., 2010, 2012; Norström \& Skog, 2005; Popova, Giesbrecht, Bekmuradov, \& Patra, 2009; Vingilis, Mcleod, Mann, \& Seeley, 2008; Yörük, 2014). A systematic review by Stockwell and Chikritzhs (2009) assessed 49 unique studies that examined the impact of a change in on-premise trading hours. They concluded that there was reliable evidence that extending 
late-night trading hours lead to increased consumption and alcohol-related harms.

A recent systematic review (Gmel, Holmes, \& Studer, 2015) examined 160 studies published between 2009 and 2014. While the authors found evidence of an association between alcohol outlet density and harm, they found little evidence of the causal direction and concluded that alcohol outlet density typically had little effect on individual-level alcohol use.

An analysis focusing on low- and middle-income countries (Cook, Bond, \& Greenfield, 2014) used archival information on alcohol policies and survey data, noting that policies that regulated the physical availability of alcohol were the most consistent predictors of alcohol consumption, with greater restrictions associated with lower alcohol consumption. Kolosnitsyna, Sitdikov, \& Khorkina (2014) used cross-sectional samples from the Russian Longitudinal Monitoring Survey to examine the impacts of a natural experiment involving variations in hours of sale. They concluded that restrictions in hours of sale, especially evening hours, were linked with lower consumption levels.

Impacts by gender or SES: From 1995 to 2004, Sweden saw a number of changes in alcohol policy that lead to a relaxation of several existing laws around the availability of alcohol. Many of these changes lead to greater access to less expensive alcohol products. During this period of transition, self-report survey measures indicated increasing Alcohol Use Disorders Identification Test (AUDIT) scores among women, a marker of higher-risk drinking patterns (Källmén, Wennberg, Berman, \& Bergman, 2007).

Impacts by age: Policies that restrict the clustering of outlets may reduce the number of successful purchases by individuals under the legal drinking age (Gruenewald, 2011). In a quasi-experimental study, restricting alcohol availability led to a reduction in alcohol-related hospitalization rates among adolescents and young adults (Wicki \& Gmel, 2011). Depending on the age group, hospitalization rates for alcoholic intoxication fell by an estimated $25-40 \%$ as the result of restricted alcohol availability.

Impacts by drinking patterns: Some studies have suggested that socially marginalized drinkers are more likely to be influenced by changes in alcohol availability than other drinkers (Livingston et al., 2007). This implies that changes to outlet density could markedly affect the consumption and long-term health problems of some population subgroups, sometimes without noticeable changes in population-level consumption estimates (Livingston et al., 2007). Later trading hours were found to be associated with increased consumption of high-risk alcoholic beverages (beverages with higher alcohol content) (Nordlund, 2010).

Impacts by alcohol-related harm: There is substantial international evidence indicating that increased physical access to alcohol is associated with a range of alcohol- related harms (Babor et al., 2003, 2010; Mann et al., 2005; McMillan \& Lapham, 2006; Popova et al., 2009; Xu et al., 2012). Livingston et al. (2007) point to links between high alcohol outlet density and STI transmission, pedestrian injuries, child maltreatment, and neighborhood amenity issues. Livingston et al. (2007) also noted that clustering of outlets, increasing the number of bars or stores close to each other, is likely to increase violence as well as promote more aggressive marketing/pricing as outlets compete with one another. A recent systematic review of the international evidence from high-income countries reports that higher alcohol outlet density is associated with medical harms, injury, crime, and violence, including suicide (Campbell et al., 2009).

With partial privatization in the Canadian province of British Columbia, a sharp increase in the density of private off-sale outlets was associated with an increase in alcohol consumption and alcohol-related mortality (Stockwell et al., 2009, 2011). A natural experiment study conducted in Kansas, USA, between 1977-2011, examined the impact of an increase in access when 85 of 105 counties voted to legalize the sale of alcohol for on-premise consumption in the outlet (Anderson, Crost, \& Rees, 2014). They reported a $10 \%$ increase in on-premise drinking establishments was associated with a $4 \%$ increase in violent crime.

However, deregulating alcohol sales and production in Japan did not appear to increase traffic fatalities and other traffic crashes in Japan (Desapriya et al., 2012). In the Canadian province of Alberta, privatization had a significant permanent effect (an increase) on the sale of spirits, but the effect was not large enough to significantly affect total sales, and there was no significant effect on the number of fatal motor vehicle traffic crashes (Trolldal, 2005).

In a time series analysis, Han, Shipp, and Gorman (2015) examined motor-vehicle crashes before and after the introduction of a large number of off-sale alcohol outlets in Lubbock, Texas, USA. The authors noted some weak effects on total crashes but no significant effects with regard to single vehicle night-time crashes, which served as an indicator for alcohol-involved crashes.

Other researchers looked at the impacts of hours and days of sales on violence. A Brazilian study looking at the effects of reducing the hours of sale for on-premise outlets on violence against women found that restricting the availability of alcohol late at night significantly reduced homicides against women (Duailibi et al., 2007). Rossow and Norström's (2011) study used a quasi-experimental design across 18 cities. They found that each one-hour extension of closing hours was associated with a statistically significant increase of 4.8 assaults. Grönqvist and Niknami (2014) studied a natural experiment during the introduction of Saturday openings of Swedish alcohol retail stores in several counties in 2000. Using a combination of data sources they found an increase in alcohol use and crime that was associated with this change in alcohol policy. 
A study in Newcastle, Australia (Kypri, McElduff, \& Miller, 2014), using a pre-post design, examined the impacts of pulling back the pub closing time from 5:00 a.m. to 3:30 a.m. in 2008. They found a lower incidence of assaults 1-18 months after the policy change, which persisted for 19-60 months.

Using a quasi-experimental design, de Goeij, Veldhuizen, Buster, and Kunst (2015) examined the impact of extending closing times of alcohol outlets in areas of Amsterdam in April 2009. After the change, they found a larger increase in the level of alcohol-related injuries in the intervention than in the control areas. They concluded that a one-hour extension in some of the city's downtown areas was associated with 34\% more alcohol-related injuries.

A study by Marcus and Siedler (2014) assessed the impacts of banning the sale of alcohol between 10 p.m. and 5 a.m. in off-premise outlets in the German state of BadenWürttemberg in 2010. An examination of monthly administrative records between 2007 and 2011 pointed to a $7 \%$ decline in alcohol-related hospitalizations among adolescents and young adults, as well as a decrease in hospitalizations due to violent assault.

However, different conclusions emerge from research by Humphreys and Eisner (2014) and Humphreys, Eisner, and Wiebe (2013). Focusing on the city of Manchester, UK, between 2004 and 2008, they did not find support for the hypothesis that staggering closing hours decreased violence nor for the alternative that increased alcohol availability resulted in increased violence.

Changes in access to alcohol have been linked with drinking and driving. Chikritzhs and Stockwell (2006) found an increase in motor vehicle crashes with an extension of closing hours in licensed premises in Western Australia. Controls on availability have been shown to be effective in reducing impaired driving. Both extending trading hours and lifting bans on Sunday alcohol trading led to increases in alcohol-related crashes and alcoholrelated crash fatalities

Mena, Sanchez, Gutierrez, Puyana, and Suffoleto (2014) examined aggregated daily counts of road traffic deaths in Cali, Columbia, from 1998 to 2008. Various levels of restrictive policies with regard to hours of sale were assessed, and the risk of motor vehicle crashes was lowest when the most restrictive policies were in effect.

In contrast, research by Green, Heywood, and Navarro (2014), focusing on extension of legal bar closing times in England and Wales, found that this change was associated with a decrease in traffic crashes, a decrease heavily concentrated among younger drivers. They note that this effect was most pronounced in the late nights and early mornings on weekends, times most directly affected by the liberalization.

\section{Studies examining both alcohol prices and alcohol availability}

We also came across research that focused on several policy measures. Two reviews focused on intimate partner violence (IPV) (Kearns, Reidy, \& Valle, 2015; Wilson, Graham, \& Taft, 2014) came to somewhat divergent conclusions. Wilson et al. (2014) focused on the period between January 1992 and March 2013. Overall, 21 studies were included. For studies on pricing, hours of sale, and outlet density there was weak evidence of impact on IPV. Kearns et al. (2015) examined 18 studies published between 1998 and 2013. They concluded that most studies of higher alcohol outlet density showed an association with higher IPV. There was limited evidence of an association between alcohol prices, or hours and days of sale, and IPV. Lippy and DeGue's (2014) review concluded that alcohol pricing, privatization, and permissive licensing policies that increased access to alcohol were related to sexual behavior in the community or higher rates of sexual violence victimization.

Xuan et al. (2015) examined 29 alcohol policies in the United States between 2004 and 2009 and related them to survey-based binge drinking measures in adults from 20052010. Based on expert input, a higher policy score was considered to reflect effectiveness and implementation and was associated with lower adjusted odds of binge drinking. Alcohol taxes and outlet density accounted for approximately half of the effect magnitude observed for all policies.

\section{Discussion}

Our thematic review found evidence that pricing and availability have a differential impact on high-risk drinkers, youth, and certain forms of alcohol-related harm. An increase in alcohol prices was associated with a reduction in alcohol consumption and several types of harms, and a decrease in prices was associated with an increase in consumption and several types of harms. A decrease in alcohol availability was shown to reduce alcohol-related harm among youth (and other sub-populations) and an increase in alcohol availability was associated with an increase in alcohol consumption in some sectors of the population and an increase in several types of alcoholrelated harms.

Alcohol policies with a harm reduction intention or potential do not only impact low-volume drinkers; these policies have demonstrated harm reduction potential among high-risk drinkers. On balance, the evidence is strongest with regard to youth and heavy drinkers. We found relatively few studies that examined the impact of policies on different ethnic and cultural groups (e.g., Montag, Clapp, Calac, Gorman, \& Chambers, 2012), and further research is recommended on this important topic and also on differential impacts associated with SES (e.g., Ayyagari, Deb, Fletcher, Gallo, \& Sindelar, 2013; Crawford et al., 2012; De Silva, Samarasinghe, \& Hanwella, 2011). 


\section{Modeling Studies}

A number of modeling studies were noted that projected differential impacts linked with demographic characteristics, drinking patterns, or type of alcohol-related harm (Anderson \& Baumberg 2006; Hollingworth et al., 2006; Holm, Veerman, Cobiac, Ekholm, \& Diderichsen, 2014; Holmes et al., 2014; Källmén et al., 2007; MacKillop \& Murphy, 2007; Meier et al., 2009; Norström et al., 2010; Patra, Rehm, \& Popova, 2011; Purshouse, Meier, Brennan, Taylor, \& Rafia, 2010; Sharma, Vandenberg, \& Hollingsworth, 2014; Sornpisarn, Shield, \& Rehm, 2012; Stockwell et al., 2013). Change in prices or taxes was the primary or a central focus in these studies, indicating, for example, that an increase in alcohol prices was projected to contribute to a reduction in high-risk drinking or alcoholrelated harm, whereas with a reduction in price, an increase in heavy drinking or alcohol-related harm was projected.

\section{Further Research}

Further work is recommended on several topics. Research might look at how policies might impact the social context and norms with regard to alcohol use. It might also focus on differential policy impact by ethnicity and SES in order to further the understanding of policy factors that target the drinking of these higher-risk groups.

Future research may also want to focus on alcohol's harms to others and the impact pricing and availability policies have on those being harmed by other's drinking, beyond the scattered literature we have noted above, mostly on violence. Policies that reduce high-risk drinking behavior are likely to also reduce harm to others from alcohol. In combination, these outcomes provide a strong case for precautionary approaches to alcohol pricing, taxation, and physical availability. The high health burden and costs associated with alcohol (Lim et al., 2012; Miller, Levy, Spicer, \& Taylor, 2006) can be reduced by implementing effective policies, including those that focus on price and physical availability.

\section{Acknowledgements}

This paper is based, in part, on a presentation at "Alcohol Policy Research: Putting Together a Global Evidence Base," a thematic meeting of the Kettil Bruun Society, Fitzroy, Melbourne, Australia, September 8-11, 2014. We thank the library staff, Centre for Addiction and Mental Health, for their contribution in locating documents.

\section{References}

Adams, M., \& Effertz, T. (2010). Effective prevention against risky underage drinking-The need for higher excise taxes on alcoholic beverages in Germany. Alcohol and Alcoholism, 45(4), 387-394. doi:10.1093/alcalc/agq031

Anderson, D. M., Crost, B., \& Rees, D. I. (2014). Wet laws, drinking establishments, and violent crime. IZA DP
8718. Bonn, Germany: Institute for the Study of Labour.

Anderson, P., \& Baumberg, B. (2006). Alcohol in Europe: A public health perspective. Institute of Alcohol Studies, United Kingdom.

Anderson, P., Chisholm, D., \& Fuhr, D. C. (2009). Effectiveness and cost-effectiveness of policies and programmes to reduce the harm caused by alcohol. Lancet, 373(9682), 2234-2246. doi:10.1016/S01406736(09)60744-3

Andreasson, S., Holder, H. D., Norström, T., Österberg, E., \& Rossow, I. (2006). Estimates of harm associated with changes in Swedish alcohol policy: Results from past and present estimates. Addiction, 101(8), 10961105. doi:10.1111/j.1360-0443.2006.01485.x

Ashton, T., Casswell, S., \& Gilmore, L. (1989). Alcohol taxes: Do the poor pay more than the rich? British Journal of Addiction, 84(7), 759-766.

Ayyagari, P., Deb, P., Fletcher, J., Gallo, W., \& Sindelar, J. L. (2013). Understanding heterogeneity in price elasticities in the demand for alcohol for older individuals. Journal of Health Economics, 22(1), 89105. doi:10.1002/hec.1817

Babor, T. F., Caetano, R., Casswell, S., Edwards, G., Giesbrecht, N., Graham, K., . . . Rossow, I. (2003). Alcohol: No ordinary commodity - Research and public policy. Oxford, England: Oxford University Press.

Babor, T. F., Caetano, R., Casswell, S., Edwards, G., Giesbrecht, N., Graham, K., . . . Rossow, I. (2010). Alcohol: No ordinary commodity - Research and public policy (2nd ed.). Oxford: Oxford University Press.

Baldwin, J. M., Stogner, J. M., \& Miller, B. L. (2014). It's five o'clock somewhere: An examination of the association between happy hour drinking and negative consequences. Substance Abuse Treatment, Prevention, and Policy, 9, 17. doi:10.1186/1747597X-9-17

Bloomfield, K., Rossow, I,. \& Norström, T. (2009) Changes in alcohol-related harm after policy changes in Denmark European Addiction Research, 15, 224231.

Brand, D. A., Saisana, M., Rynn, L. A., Pennoni, F., \& Lowenfels, A. B. (2007). Comparative analysis of alcohol control policies in 30 Countries. PLOS Medicine, 4(4), e151.

Bruun, K., Edwards, G., Lumio, M., Mäkelä, K., Pan, L., Popham, R. E., . . . Österberg, E. (1975). Alcohol control policies in public health perspective (Vol. 25). Helsinki, Finland: Finnish Foundation for Alcohol Studies.

Byrnes, J., Shakeshaft, A., Petrie, D., \& Doran, C. (2013). Can harms associated with high-intensity drinking be reduced by increasing the price of alcohol? Drug and Alcohol Review, 32(1), 27-30. doi:10.1111/j.14653362.2012.00482.x

Campbell, C. A., Hahn, R. A., Elder, R., Brewer, R., Chattopadhyay, S., Fielding, J., . . . Middleton, J. C., Task Force of Community Preventive Services. (2009). The effectiveness of limiting alcohol outlet density as a means of reducing excessive alcohol 
consumption and alcohol-related harms. American Journal of Preventive Medicine, 37(6), 556-569. doi:10.1016/j.amepre.2009.09.028

Canadian Public Health Association. (2011). Too high a cost - A public health approach to alcohol policy in Canada. Ottawa, Canada: Canadian Public Health Association.

Chaloupka, F. J., Grossman, M., \& Saffer, H. (2002). The effects of price on alcohol consumption and alcoholrelated problems. Alcohol Research \& Health, 26(1), 22-34.

Chick, J. (2011). The WHO global strategy to reduce the harmful use of alcohol. Alcohol and Alcoholism, 46(3), 223. doi:10.1093/alcalc/agr035

Chikritzhs, T., \& Stockwell, T. (2006). The impact of later trading hours for hotels on levels of impaired driver road crashes and driver breath alcohol levels. Addiction, 101(9), 1254-1264. doi:10.1111/j.1360 0443.2006.01487.x

Cook, W. K., Bond, J., \& Greenfield, T. K. (2014). Are alcohol policies associated with alcohol consumption in low- and middle-income countries? Addiction, 109(7), 1081-1090. doi:10.1111/add.12571

Crawford, M. J., Parry, A. M., Weston, A. R., Seretis, D., Zauter-Tutt, M., Hussain, A., . . . North, B. (2012). Relationship between price paid for off-trade alcohol, alcohol consumption and income in England: A crosssectional survey. Alcohol and Alcoholism, 47(6), 738742. doi:10.1093/alcalc/ags091

Crombie, I. K., Irvine, L., Elliott, L., \& Wallace, H. (2007). How do public health policies tackle alcohol-related harm: A review of 12 developed countries. Alcohol and Alcoholism, 42(5), 492-499. doi:10.1093/alcalc/ agm001

de Goeij, M. C., Veldhuizen, E. M., Buster, M. C., \& Kunst, A. E. (2015). The impact of extended closing times of alcohol outlets on alcohol-related injuries in the nightlife areas of Amsterdam: A controlled beforeand-after evaluation. Addiction, 110(6), 955-964. doi:10.1111/add.12886

de Silva, V., Samarasinghe, D., \& Hanwella, R. (2011). Association between concurrent alcohol and tobacco use and poverty. Drug and Alcohol Review, 30(1), 6973. doi:10.1111/j.1465-3362.2010.00202.x

Desapriya, E., Fujiwara, T., Dutt, N., Arason, N, \& Pike, I. (2011). Impact of the 1994 alcohol production and sales deregulation policy on traffic crashes and fatalities in Japan. Asia-Pacific Journal of Public Health, 24(5), 776-785.

Diaz, M. C., Chaloupka, F. J., \& Jernigan, D. H. (2015). The effects of alcohol excise tax increases on public health and safety in Texas. Austin, TX, United States: Texans Standing Tall.

Duailibi, S., Ponicki, W., Grube, J., Pinsky, I., Laranjeira, R., \& Raw, M. (2007). The effect of restricting opening hours on alcohol-related violence. American Journal of Public Health, 97(12), 2276-2280. doi:10.2105/AJPH.2006.092684

Edwards, G. A. P., Babor, T. F., Casswell, S., Ferrence, R., Giesbrecht, N., Godfrey, C., . . . Skög, O. -J. (1994). Alcohol policy and the public good. New York, NY, United States: Oxford University Press.
Fone, D., Dunstan, F., White, J., Webster, C., Rodgers, S., Lee, S., . . . Lyons, R. (2012). Change in alcohol outlet density and alcohol-related harm to population health (CHALICE). BMC Public Health, 12, 428. doi:10.1186/1471-2458-12-428

Foster, J. H., \& Ferguson, C. (2014). Alcohol 'pre-loading': A review of the literature. Alcohol and Alcoholism, 49(2), 213-226. doi:10.1093/alcalc/agt135

Gallet, C. A. (2007). The demand for alcohol: A metaanalysis of elasticities. Australian Journal of Agricultural and Resource Economics, 51(2), 14. doi:10.1111/j.1467-8489.2007.00365.x

Giesbrecht, N., Stockwell, T., Kendall, P., Strang, R., \& Thomas, G. (2011). Alcohol in Canada: Reducing the toll through focused interventions and public health policies. Canadian Medical Association Journal, 183(4), 450-455. doi:10.1503/cmaj.100825

Giesbrecht, N., Wettlaufer, A., April, N., Asbridge, M., Cukier, S., Mann, R., . . . Vallance, K. (2013). Strategies to reduce alcohol-related harms and costs in Canada: A comparison of provincial policies. Toronto, Canada: Centre for Addiction and Mental Health.

Gmel, G., Holmes, J., \& Studer, J. (2015). Are alcohol outlet densities strongly associated with alcoholrelated outcomes? A critical review of recent evidence. Drug and Alcohol Review, 35(1), 40-54. doi:10.1111/dar.12304

Goodman, A. C. (2009). Economic analyses of multiple addictions for men and women. Journal of Mental Health Policy and Economics, 12(3), 139-155.

Green, C. P., Heywood, J. S., \& Navarro, M. (2014). Did liberalising bar hours decrease traffic accidents? Journal of Health Economics, 35, 189-198. doi:10.1016/j.jhealeco.2014.03.007

Grabauskas V., Prochorskas, R., \& Verga, A. (2009) Associations between mortality and alcohol consumption in Lithuanian population. Medicina (Kaunas, Lithuania), 45(12), 1000-1012.

Grönqvist, H., \& Niknami, S. (2014). Alcohol availability and crime: Lessons from liberalized weekend sales restrictions. Journal of Urban Economics, 81, 7.

Grossman, M., Chaloupka, F. J., Saffer, H., \& Laixuthai, A. (1995). Effects of alcohol price policy on youth: A summary of economic research. In G. M. Boyd, J. Howard, \& R. A. Zucker (Eds.), Alcohol problems among adolescents: Current directions in prevention research (pp. 225-242). Hillsdale, NJ, United States: Lawrence Erlbaum Associates.

Grube, J. W., \& Nygaard, P. (2005). Alcohol policy and youth drinking: Overview of effective interventions for young people. In T. Stockwell, P. J. Gruenewald, J. W. Toumbourou, \& W. Loxley (Eds.), Preventing harmful substance use: The evidence base for policy and practice (pp. 113-127). New York, NY, United States: John Wiley and Sons.

Gruenewald, P. J. (2011). Regulating availability: How access to alcohol affects drinking and problems in youth and adults. Alcohol Research \& Health, 34(2), 248-256. doi:SPS-AR\&H-39

Hahn, R. A., Kuzara, J. L., Elder, R., Brewer, R., Chattopadhyay, S., Fielding, J., . . . Lawrence, B., 
Task Force on Community Preventive Services. (2010). Effectiveness of policies restricting hours of alcohol sales in preventing excessive alcohol consumption and related harms. American Journal of Preventive Medicine, 39(6), 590-604. doi:10.1016/ j.amepre.2010.09.016

Hahn, R. A., Middleton, J. C., Elder, R., Brewer, R., Fielding, J., Naimi, T. S., . . . Campbell, C. A.; Community Preventive Services Task Force. (2012). Effects of alcohol retail privatization on excessive alcohol consumption and related harms: A community guide systematic review. American Journal of Preventive Medicine, 42(4), 418-427. doi:10.1016/ j.amepre.2012.01.002

Han, D., Shipp, E. M., \& Gorman, D. M. (2015). Evaluating the effects of a large increase in off-sale alcohol outlets on motor vehicle crashes: A time-series analysis. International Journal of Injury Control and Safety Promotion, 22(4), 320-327. doi:10.1080/ 17457300.2014. 908223

Helakorpi, S., Mäkelä, P., \& Uutela, A. (2010). Alcohol consumption before and after a significant reduction of alcohol prices in 2004 in Finland: Were the effects different across population subgroups? Alcohol \& Alcoholism, 45(3), 286-292. doi:10.1093/alcalc/ agq007

Herttua, K., Mäkelä, P., Martikainen, P., \& Sirén, R. (2008). The impact of a large reduction in the price of alcohol on area differences in interpersonal violence: A natural experiment based on aggregate data. Journal of Epidemiology \& Community Health, 62(11), 9951001. doi:10.1136/jech.2007.069575

Hollingworth, W., Ebel, B. E., McCarty, C. A., Garrison, M. M., Christakis, D. A., \& Rivara, F. P. (2006). Prevention of deaths from harmful drinking in the United States: The potential effects of tax increases and advertising bans on young drinkers. Journal of Studies on Alcohol and Drugs, 67(2), 300-308.

Holm, A. L., Veerman, L., Cobiac, L., Ekholm, O., \& Diderichsen, F. (2014). Cost-effectiveness of changes in alcohol taxation in Denmark: A modelling study. Cost Effectiveness and Resource Allocation, 12(1), 1. doi:10.1186/1478-7547-12-1

Holmes, J., Meng, Y., Meier, P. S., Brennan, A., Angus, C., Campbell-Burton, A., . . . Purshouse, R. C. (2014). Effects of minimum unit pricing for alcohol on different income and socioeconomic groups: A modelling study. Lancet, 383(9929), 1655-1664. doi:10.1016/S0140-6736(13)62417-4

Humphreys, D. K., \& Eisner, M. P. (2014). Do flexible alcohol trading hours reduce violence? A theory-based natural experiment in alcohol policy. Social Science \& Medicine, 102, 1-9. doi:10.1016/j.socscimed.2013. 11.038

Humphreys, D. K., Eisner, M. P., \& Wiebe, D. J. (2013). Evaluating the impact of flexible alcohol trading hours on violence: An interrupted time series analysis. PLoS One, 8(2), e55581. doi:10.1371/journal.pone.0055581

Jones, S. C., \& Barrie, C. (2011). RTDs in Australia: Expensive designer drinks or cheap rocket fuel? Drug and Alcohol Review, 30(1), 4-11.
Jones, S. C., \& Smith, K. M. (2011). The effect of point of sale promotions on alcohol purchasing behaviour of young people in metropolitan, regional and rural Australia. Journal of Youth Studies, 14(8), 885-900.

Källmén, H., Wennberg, P., Berman, A. H., \& Bergman, H. (2007). Alcohol habits in Sweden during 1997-2005 measured with the AUDIT. Nordic Journal of Psychiatry, 61(6), 466-470. doi:10.1080/ 08039480701773303

Karlsson, T., \& Österberg, E. (2001). A scale of formal alcohol control policy in 15 European countries. Nordisk Alkohol- \& Narkotikatidskrift, 18, 117-131.

Kearns, M. C., Reidy, D. E., \& Valle, L. A. (2015). The role of alcohol policies in preventing intimate partner violence: A review of the literature. Journal of Studies on Alcohol and Drugs, 76(1), 21-30.

Kolosnitsyna, M., Sitdikov, M., \& Khorkina, N. (2014). Availability restrictions and alcohol consumption: A case of restricted hours of alcohol sales in Russian regions. The International Journal of Alcohol And Drug Research, 3(3), 193-201. doi:10.7895/ ijadr.v3i3.154

Kypri, K., McElduff, P., \& Miller, P. (2014). Restrictions in pub closing times and lockouts in Newcastle, Australia five years on. Drug and Alcohol Review, 33(3), 323-326. doi:10.1111/dar.12123

Lhachimi, S. K., Cole, K. J., Nusselder, W. J., Smit, H. A., Baili, P., Bennett, K., . . . Boshuizen, H. (2012). Health impacts of increasing alcohol prices in the European Union: A dynamic projection. American Journal of Preventive Medicine, 55(3), 237-243. doi:10.1016/j.ypmed.2012.06.006

Lim, S. S., Vos, T., Flaxman, A. D., Danaei, G., Shibuya, K., Adair-Rohani, H., . . . Memish, Z. A. (2012). A comparative risk assessment of burden of disease and injury attributable to 67 risk factors and risk factor clusters in 21 regions, 1990-2010: A systematic analysis for the Global Burden of Disease Study 2010. Lancet, 380(9859), 2224-2260. doi:10.1016/S01406736(12)61766-8

Lin, C. M., \& Liao, C. M. (2014). Inpatient expenditures on alcohol-attributed diseases and alcohol tax policy: A nationwide analysis in Taiwan from 1996 to 2010. Public Health, 128(11), 977-984. doi:10.1016/ j.puhe.2014.09.004

Lippy, C., \& DeGue, S. (2014). Exploring alcohol policy approaches to prevent sexual violence perpetration. Trauma, Violence \& Abuse, 17(1), 26-42. doi:10.1177/152483801455729

Livingston, M., Chikritzhs, T., \& Room, R. (2007). Changing the density of alcohol outlets to reduce alcohol-related problems. Drug and Alcohol Review, 26(5), 557-566.

Ludbrook, A., Holmes, J., \& Stockwell, T. (2014). Gender differences in alcohol demand: A systematic review of the role of prices and taxes. Comment on conclusions by Nelson. Journal of Health Economics, 23(10), 1281-1283. doi:10.1002/hec.3096

MacKillop, J., \& Murphy, J. G. (2007). A behavioural economic measure of demand for alcohol predicts brief intervention outcomes. Drug and Alcohol Dependence, 89(2-3), 227-233. 
Mäkelä, P., \& Österberg, E. (2009). Weakening of one more alcohol control pillar: A review of the effects of the alcohol tax cuts in Finland in 2004. Addiction, 104(4), 554-563. doi:10.1111/j.1360-0443.2009. 02517.x

Mäkelä, P., Rossow, I., \& Tryggvesson, K. (2002). Who drinks more or less when policies change? The evidence from 50 years of Nordic studies. In R. Room (Ed.), The effects of Nordic alcohol policies. What happens to drinking and harm when alcohol controls change? Helsinki, Finland: Nordic Council for Alcohol and Drug Research.

Mann, R. E., Rehm, J. T., Giesbrecht, N., Room, R., Edward Adlaf, E., Gmel, G., .. . Roerecke, M. (2005). Alcohol distribution, alcohol retailing and social responsibility. Toronto, Ontario, Canada: Beverage Alcohol System Review Panel.

Marcus, J., \& Siedler, T. (2014). Reducing binge drinking? The effect of a ban on late-night off-premise alcohol sales on alcohol-related hospital stays in Germany. Journal of Public Economics, 123, 55-77.

McMillan, G. P., \& Lapham, S. (2006). Effectiveness of bans and laws in reducing traffic deaths: Legalized Sunday packaged alcohol sales and alcohol-related traffic crashes and crash fatalities in New Mexico. American Journal of Public Health, 96(11), 1944 1948. doi:10.2105/AJPH.2005.069153

Meier, P. S., Purshouse, R., \& Brennan, A. (2009). Policy options for alcohol price regulation: The importance of modelling population heterogeneity. Addiction, 105(3), 383-393. doi:10.1111/j.1360-0443.2009. 02721.x

Mena, J., Sanchez, A. I., Gutierrez, M. I., Puyana, J.-C., \& Suffoleto, B. (2014). The association between alcohol restriction policies and motor vehicle-related mortality in Cali, Columbia, 1998-2008. International Journal of Alcohol and Drug Research, 3(2), 149-158. doi:10.7895/ijadr.v3i2.157

Miller, T. R., Levy, D. T., Spicer, R. S., \& Taylor, D. M. (2006). Societal costs of underage drinking. Journal of Studies on Alcohol and Drugs, 67(4), 519-528.

Montag, A., Clapp, J. D., Calac, D., Gorman, J., \& Chambers, C. (2012). A review of evidence-based approaches for reduction of alcohol consumption in Native women who are pregnant or of reproductive age. American Journal of Drug and Alcohol Abuse, 38(5), 436-443. doi:10.3109/00952990.2012.694521

Nelson, T. F., Xuan, Z., Babor, T. F., Brewer, R. D., Chaloupka, F. J., Gruenewald, P. J., . . . Naimi, T. S. (2013). Efficacy and the strength of evidence of U.S. alcohol control policies. American Journal of Preventive Medicine, 45(1), 19-28. doi:10.1016/ j.amepre.2013.03.008

Nordlund, S. (2010). Effects of increasing availability of wine and spirits in Norway. Nordic Studies on Alcohol and Drugs, 27, 127-140.

Norström, T., Miller, T., Holder, H., Österberg, E., Ramstedt, M., Rossow, I., \& Stockwell, T. (2010). Potential consequences of replacing a retail alcohol monopoly with a private licence system: Results from Sweden. Addiction, 105(12), 2113-2119. doi:10.1111/ j.1360-0443.2010.03091.x
Norström, T., \& Skog, O. J. (2005). Saturday opening of alcohol retail shops in Sweden: An experiment in two phases. Addiction, 100(6), 767-776. doi:10.1111/ j.1360-0443.2005.01068.x

O’Mara, R. J., Thombs, D. L., Wagenaar, A. C., Rossheim, M. E., Merves, M. L., Hou, W., . . . Goldberger, B. A. (2009). Alcohol price and intoxication in college bars. Alcoholism: Clinical and Experimental Research, 33(11), 1973-1980. doi:10.1111/j.1530-0277.2009. 01036.x

Parsons, A. G., \& Stephenson, N. (2013). Effects of price and alcohol content on purchase behavior: An analysis of Australian and New Zealand youth drinking. Young Consumers, 14(2), 112-121.

Paschall, M. J., Grube, J. W., \& Kypri, K. (2009). Alcohol control policies and alcohol consumption by youth: A multi-national study. Addiction, 104(11), 1849-1855.

Patra, J., Giesbrecht, N., Rehm, J., Bekmuradov, D., \& Popova, S. (2012). Are alcohol prices and taxes an evidence-based approach to reducing alcohol-related harm and promoting public health and safety? A literature review. Contemporary Drug Problems, 39(1), 7-48.

Patra, J., Rehm, J., \& Popova, S. (2011). Avoidable alcohol-attributable criminality and its costs due to selected interventions in Canada. International Journal of Drug Policy, 22(2), 109-119. doi:10.1016/j.drugpo.2010.10.008

Ponicki, W. R., Gruenewald, P. J., \& LaScala, E. A. (2007). Joint impacts of minimum legal drinking age and beer taxes on US youth traffic fatalities, 1975 to 2001. Alcoholism: Clinical and Experimental Research, 31(5), 804-813. doi:10.1111/j.1530-0277.2007. 00363.x

Popova, S., Giesbrecht, N., Bekmuradov, D., \& Patra, J. (2009). Hours and days of sale and density of alcohol outlets: Impacts on alcohol consumption and damage: A systematic review. Alcohol and Alcoholism, 44(5), 500-516. doi:10.1093/alcalc/agp054

Purshouse, R. C., Meier, P. S., Brennan, A., Taylor, K. B., \& Rafia, R. (2010). Estimated effect of alcohol pricing policies on health and health economic outcomes in England: An epidemiological model. Lancet, 375(9723), 1355-1364. doi:10.1016/S0140-6736(10) 60058-X

Razvodovsky, Y. E. (2013). Affordability of alcohol and alcohol-related mortality in Belarus. Adicciones, 25(2), 156-162.

Room, R. (Ed.). (2002). The effects of Nordic alcohol policies: What happens to drinking and harm when alcohol controls change? Helsinki, Finland: Nordic Council for Alcohol and Drug Research.

Room, R. (2004) Effects of alcohol controls: Nordic research traditions. Drug and Alcohol Review, 23, 4353.

Room, R., Bloomfield, K., Gmel, G., Grittner, U., Gustafsson, N., Mäkelä, P., . . . Wicki, M. (2013). What happened to alcohol consumption and problems in the Nordic countries when alcohol taxes were decreased and borders opened? The International Journal of Alcohol And Drug Research, 2(1), 77-87. doi:10.7895/ijadr.v2i1.58 
Rose, P., Smith, S. T., \& Segrist, D. J. (2010). Too cheap to chug: Frugality as a buffer against college-student drinking. Journal of Consumer Behaviour, 9(3), 228238.

Rossow, I., \& Norström, T. (2011). The impact of small changes in bar closing hours on violence. The Norwegian experience from 18 cities. Addiction, 107(3), 530-537. doi:10.1111/j.1360-0443.2011. 03643. $\mathrm{x}$

Saar, I. (2015). Do alcohol excise taxes affect traffic accidents? Evidence from Estonia. Traffic Injury Prevention, 16, 213-218. doi:10.1080/15389588.2014. 933817

Saffer, H., \& Dave, D. (2006). Alcohol advertising and alcohol consumption by adolescents. Journal of Health Economics, 15(6), 617-637. doi:10.1002/ hec.1091

Seaman, P., Edgar, F., \& Ikegwuonu, T. (2013). The role of alcohol price in young adult drinking cultures in Scotland. Drugs (Abingdon, England), 20(4), 278285. doi:10.3109/09687637.2013.765386

Sharma, A., Vandenberg, B., \& Hollingsworth, B. (2014). Minimum pricing of alcohol versus volumetric taxation: Which policy will reduce heavy consumption without adversely affecting light and moderate consumers? PLoS One, 9(1), e80936. doi:10.1371/ journal.pone.0080936

Skidmore, J. R., \& Murphy, J. G. (2011). The effect of drink price and next-day responsibilities on college student drinking: A behavioral economic analysis. Psychology of Addictive Behaviors, 25(1), 57-68. doi:10.1037/a0021118

Sornpaisarn, B., Shield, K. D., \& Rehm, J. (2012). Alcohol taxation policy in Thailand: Implications for other low- to middle-income countries. Addiction, 107(8), 1372-1384. doi:10.1111/j.1360-0443.2011.03681.x

Staras, S. A., Livingston, M. D., Christou, A. M., Jernigan, D. H., \& Wagenaar, A. C. (2014). Heterogeneous population effects of an alcohol excise tax increase on sexually transmitted infections morbidity. Addiction, 109(6), 904-912. doi:10.1111/add.12493

Stockwell, T., \& Chikritzhs, T. (2009). Do relaxed trading hours for bars and clubs mean more relaxed drinking? A review of international research on the impacts of changes to permitted hours of drinking. Crime Prevention \& Community Safety, 11, 153-170.

Stockwell, T., Gruenewald, P., Toumbourow, J., \& Loxley, W. (2005). Preventing harmful substance use: The evidence base for policy and practice. New York, NY, United States: Wiley.

Stockwell, T., Zhao, J., Giesbrecht, N., Macdonald, S., Thomas, G., \& Wettlaufer, A. (2012). The raising of minimum alcohol prices in Saskatchewan, Canada: Impacts on consumption and implications for public health. American Journal of Public Health, 102(12), e103-e110. doi:10.2105/AJPH.2012.301094

Stockwell, T., Zhao, J., Macdonald, S., Pakula, B., Gruenewald, P., \& Holder, H. (2009). Changes in per capita alcohol sales during the partial privatization of British Columbia's retail alcohol monopoly 20032008: A multi-level local area analysis. Addiction,
104(11), 1827-1836. doi:10.1111/j.1360-0443.2009. 02658.x

Stockwell, T., Zhao, J., Macdonald, S., Vallance, K., Gruenewald, P., Ponicki, W., . . . Treno, A. (2011). Impact on alcohol-related mortality of a rapid rise in the density of private liquor outlets in British Columbia: A local area multi-level analysis. Addiction, 106(4), 768-776. doi:10.1111/j.1360-0443. 2010.03331.x

Stockwell, T., Zhao, J., Martin, G., Macdonald, S., Vallance, K., Treno, A., . . . Buxton, J. (2013). Minimum alcohol prices and outlet densities in British Columbia, Canada: Estimated impacts on alcoholattributable hospital admissions. American Journal of Public Health, 103(11), 2014-2020. doi:10.2105/ AJPH.2013.301289

Trolldal, B. (2005). An investigation of the effect of privatization of retail sales of alcohol on consumption and traffic accidents in Alberta, Canada. Addiction, 100(5), 662-671. doi:10.1111/j.1360-0443.2005. 01049.x

Vingilis, E., Mcleod, A. I., Mann, R. E., \& Seeley, J. (2008). A tale of two cities: The effect of extended drinking hours in licensed establishments on impaired driving and assault charges. Traffic Injury Prevention, 9(6), 527-533. doi:10.1080/15389580802344788

Wagenaar, A. C., Livingston, M. D., \& Staras, S. S. (2015). Effects of a 2009 Illinois alcohol tax increase on fatal motor vehicle crashes. American Journal of Public Health, 105(9), 1880-1885. doi:10.2105/AJPH.2014. 302428

Wagenaar, A. C., Salois, M. J., \& Komro, K. A. (2009). Effects of beverage alcohol price and tax levels on drinking: A meta-analysis of 1003 estimates from 112 studies. Addiction, 104(2), 179-190. doi:10.1111/j. 1360-0443.2008.02438.x

Wagenaar, A. C., Tobler, A. L., \& Komro, K. A. (2010). Effects of alcohol tax and price policies on morbidity and mortality: A systematic review. American Journal of Public Health, 100(11), 2270-2278. doi:10.2105/ AJPH.2009.186007

Wicki, M., \& Gmel, G. (2011). Hospital admission rates for alcoholic intoxication after policy changes in the canton of Geneva, Switzerland. Drug and Alcohol Dependence, 118(2-3), 209-215. doi:10.1016/j. drugalcdep.2011.03.020

Wilson, I. M., Graham, K., \& Taft, A. (2014). Alcohol interventions, alcohol policy and intimate partner violence: A systematic review. BMC Public Health, 14, 881. doi:10.1186/1471-2458-14-881

World Health Organization. (2010). Global strategy to reduce the harmful use of alcohol. Geneva, Switzerland: World Health Organization.

Xin, X., \& Chaloupka, F. J. (2011). The effects of prices on alcohol use and its consequences. Alcohol Research \& Health, 34(2), 236-245. doi:SPS-AR\&H-26

Xu, Y., Yu, Q., Scribner, R., Theall, K., Scribner, S., \& Simonsen, N. (2012). Multilevel spatiotemporal change-point models for evaluating the effect of an alcohol outlet control policy on changes in neighborhood assaultive violence rates. Spatial and 
Spatio-temporal Epidemiology, 3(2), 121-128. doi:10.1016/j.sste.2012.04.005

Xuan, Z., Blanchette, J., Nelson, T. F., Heeren, T., Oussayef, N., \& Naimi, T. S. (2015). The alcohol policy environment and policy subgroups as predictors of binge drinking measures among US adults. American Journal of Public Health, 105(4), 816-822. doi:10.2105/AJPH.2014.302112

Yörük, B. K. (2014). Legalization of Sunday alcohol sales and alcohol consumption in the United States. Addiction, 109(1), 55-61. doi:10.1111/add.12358

Zatoński, W. A., Sulkowska, U., Zatoński, M. Z., Herbeć, A. A., \& Muszyńska, M. M. (2015). Alcohol taxation and premature mortality in Europe. Lancet, 385(9974), 1181. doi:10.1016/S0140-6736(15)60634-1 